\title{
E-Participation: an investigation of Government Readiness in the Kingdom of Bahrain
}

\author{
Hayat Ali and Tahera Ali \\ Department of Information Systems, University of Bahrain
}

Correspondence should be addressed to: Hayat Ali; hali@uob.edu.bh

Received date: 21 July 2014; Accepted date: 22 December 2014; Published date: 8 December 2015

Academic Editor: Popescu Gh. Cristina Raluca

Copyright (C) 2015. Hayat Ali and Tahera Ali. Distributed under Creative Commons CC-BY 4.0

\begin{abstract}
Nowadays, governments around the world started recognizing the importance of involving citizens in decision process making through what is called e-Participation. E-Participation is the use of Technology to enhance involving citizens in decision making in order to increase transparency and enhance communication between governments and citizens. EParticipation by its real mean is now applied in the Kingdom of Bahrain. This research is to investigate the readiness of e-Participation implementation in the Kingdom. To achieve this aim, an e-Government Authority's initiative that is responsible for the implementation of eParticipation in the Kingdom was evaluated using a framework from the literature. The results showed that the Kingdom of Bahrain is ready to implement e-Participation as there were good initiatives with relation to the ten dimensions of the framework considered in this research. This research provides the government of the Kingdom of Bahrain with insights on the dimensions and factors that are important to enhance the readiness of e-Participation implementation.
\end{abstract}

Keywords: e-Participation, implementaion , readiness, Government , Kingdom of bahrain

\section{Introduction}

The potential of Information and Communication Technologies (ICTs) to increase political Participation is growing around the world. E-Participation has become a term that is used widely. EParticipation is the electronic form that is part of both e-Democracy and eGovernance. Islam (2008) pointed out that e-Participation is built on ICT to develop the interaction in both governance and government. From different points of view, Brown (2004) who is affected by modern science indicated that e-Participation employs the liberal democracy standards including transparency, uncertainty, problem solving, strong capital and security that help developing a more rational and effective policy.

E-Participation implementation can be considered from different dimensions that should be evaluated to assure its success. According to Macintosh (2004) in categorizing the dimensions of eparticipation, e-Participation dimensions are the levels of participation, stages in

Cite this Article as: Hayat Ali and Tahera Ali (2015)," E-Participation: an investigation of Government Readiness in the Kingdom of Bahrain", Journal of e-Government Studies and Best Practices, Vol. 2015 (2015), Article ID 473662, DOI: 10.5171/2015.473662 
policy making process, actors and roles, technologies used, rules of engagement, duration \& sustainability, types of engagement, accessibility, resources and Promotion, Evaluation and outcomes, and Critical factors for success. Other researchers such as Tambouris et al. (2007) and Panopoulou et al. (2008) derived their assessments based on Macintosh (2004)'s dimensions.

Currently, the Kingdom of Bahrain is applying e-Participation by its real mean. Therefore, this research is to investigate the government readiness of eParticipation implementation using Macintosh (2004)'s framework.

The rest of the paper is organized as follows: first, the e-Participation implementation dimensions are discussed in details, then these dimensions are reflected on the context of the Kingdom of Bahrain, and finally this paper is ended up with a conclusion and future works.

\section{E-Participation Implementation Dimensions}

Any service implemented by e-government projects follows guidelines and processes. These guidelines are either acquired from previous researchers or are part of a project and have been derived from long research and development process. The following sections present the ten dimensions presented by Macintosh (2004) that were used by other researchers (Tambouris et al. ,2007; Panopoulou et al. ,2008) that is the base for this research.

\section{Levels of Participation:}

There are different levels of e-Participation that were presented by many authors. Arnstein (1969) stressed that participation can take place in eight levels starting from non-participation level such as (1) Manipulation, (2) Therapy, to the one direction participation in level (3) Information, (4) Consultation, and finally to the high level of participation which include 5) Placation, (6) Partnership, (7) delegated power and (8) citizens control that is based on giving citizens a high power to participate. According to the UN (2014), three main types of interaction can take place between citizens and government which are differentiated according to the purpose, type of communication and the tools that can be used which include e-Information, eConsultation and e-Decision. In addition, Bremen (2008) presented six forms of eParticipation, including: 1) informational, 2) Transparency through third parties, 3) Consultation, 4) Applications complaints / petitions, 5) Cooperation, and 6) Activism / campaigns/ lobbying. Comparing to UN categorization, researcher noted that Bremen extended each level to two levels that reflects characteristics from the upper and the lower levels. Finally Macintosh (2004) presented three e-Participation levels including e-enabling, e-engaging and e-empowering that is identical with UN categorization. E-enabling at which the citizens know and are updated with government practices; at E-engaging level, the citizens engage in decision making by exchanging the comments and feedback; and at the e-empowerment level, the citizens are given the power to take decision making and decide on their future. Considering all the above ways of categorizing e-Participation, Islam (2008) has mapped them to each other

\section{Stages in Policy-Making Process}

Any project should go through a certain process to achieve the required results. eParticipation is one of the projects to which an e-government draws attentions with regards to setting a plan of process and resources in terms of achieving the required results. This dimension is about the sequences that e-participation project should go through. Macintosh (2004) categorizes the policy making process into five processes which are: Agenda setting, Analysis, Creating the policy, implementing the policy, and monitoring the policy. On the other hand, DiNitto and Johnson (2011) identify five processes of policy making in government. These processes start with identifying policy problems, passing through Formulating policy proposals, Legitimizing public policy, and Implementing public policy, and ending 
with Evaluating public policy. Both researchers categorized the policy making process into five processes and identified these processes with the same definition but in different synonyms as follows:

a. Identifying policy problems \agenda setting: This process is identifying the needs of the policy process. The needs could be policy problem, improving the current situation, or a new opportunity which impacts the current situations.

b. Formulating policy proposals \ Analysis: identify all effects and influences on the policy making process. It also includes "gathering evidence and knowledge from the arrangement of sources including citizens and civil society organizations, and understanding the context, including the political context for the agenda item" (Macintosh, 2004)

c. Legitimizing public policy $\backslash$ Creating the policy: is the outcome of the analysis process in which the policy will be created after a long process of analysis, system approving, risk management, and budget allocation.

d. Implementing public policy: is to implement the created policy by providing the interest people "with development of legislation, regulation, guidance, and a delivery plan". (Macintosh, 2004)

e. Evaluating public policy \'monitoring the policy: to evaluate and monitor the created policy in the real context, by the interest group.

\section{Actors and Roles}

It is also known as E-democracy community, (democratic actors) that includes all people providing, implementing, benefitting or involving in the democratic sector. Actors of eParticipation represent the core area in the e-participation framework, because these actors represent the beneficiaries of this technology. We can divide actors in eparticipation in two different forms, first according to the type of stakeholders and the other according to the OECD (2008)'s behavioral perspective of citizens to participate.

Referring to the first type of categorizing the actors, Clift (2003) listed eParticipation actors as governments elected officials, media (and major online portals), political parties and interest groups, civil society organization, international governmental organizations, and Citizens/voters. Macintosh (2004) indicated that e-Participation actors should include: who to engage with in eparticipation services, and what roles are of each participant. These actors include "government ministers, citizens, elected representatives, policy implementers, policy-makers, businesses and civil society organizations (CSOs)" (Macintosh, 2004). DEMO-net (2008) also divides the stakeholders of e-participation to eight categories. These actors are Elected Representatives, government, political parties and politicians, Non-Governmental Organizations (NGOs) and Civil Society Organizations (CSOs) citizens groups, academia and research, others include mass communication media. All researchers agreed that government organization, citizens, and civil society organizations are the main part of the eparticipation actors in which eparticipation services are not useful if one of these actors is not engaged.

The second type of categorizing is dependent on the behavioral perspective. Before going through the most important theory of e-Participation, we must distinguish between the requirement of eParticipation such as openness and inclusion. Openness means the readiness to acquire new experience, ideas and technology. According to OECD (2008) openness refers to the availability of the information to citizens and the establishment of an access with a 
responsive policy process. Inclusion on the other hand is about including the citizens' ideas, views and voices in policy development as possible.

The government is dealing with different people in e-Participation process. Therefore, the government should have different techniques to deal with this personality diversion, in terms of involving them in the policy making process. According to OECD (2008), the different types of e-Participation members are:

People who are "willing and able": they are interested in participating in the policy process, have all skills and experiences to participate, there is no barrier to include them in the participation process, and they are returning a benefit to the decision process.

People who are "able but unwilling": they usually have all resources to participate but they are unwilling because they are not ready, believing and trusting the government, or they do not have an interest in participating.

People who are "willing but unable": they are interested in participating in policy making but they have some barriers such as: cultural or language barriers, geographical distance, disability or socioeconomic status.

People who are "unwilling and unable": they are not ready to get involved in policy making, they do not have any background about democracy, participation or policy development, they prefer to be away from participation, and they do not care to give their voice because they usually have simple livelihoods.

These types of people must be considered when adopting e-Participation, because citizens with different educational backgrounds, attitudes and interests must be involved in policies' development.

\section{Technologies}

The Technology dimension includes all ICT tools, software that answer the question how citizens can be engaged and with what (Macintosh, 2004). Tambouris et al.(2007) establish a framework with three levels of analysis of E-participation technology which are the participation area, tools categories, and technologies. Participation areas include the fundamental process of eparticipation, and citizens' participation areas. The other part is ICT and has been represented by the categories of tools that are based on technologies.

The three levels are further described below:

\section{Participation Areas}

It includes the core characteristics in which the e-Participation has been implemented. Tambouris et al. (2007) emphasize the importance of this layer through sharing the politicians' views, examining the views in different perspectives, making political decision, deploying transparency in all political areas and allowing the engagement in the political decision process.

The Participation areas include all the areas that citizens can interact with the government, Tambouris et al. (2007) and DEMO-net (2008) agreed that the eparticipation of a certain country could include one or more of the following areas: Community $\backslash$ Information Provision, Discourse, Community building / Collaborative Environments, Mediation, Consultation, Spatial planning, Campaigning, Polling, Electioneering, Voting, and Deliberation.

\section{Categories of Tools}

It is the second layer of participation analysis that supports the participation areas' layer. This layer includes all software and services provided to the target stakeholders in order to achieve the desired outcomes.

According to Tambouris et al. (2007), eparticipation tools include Weblogs, Web Portals, Search Engines, Webcasting / Podcasting, Mailing Lists / Newsgroups, Chat Rooms, Wikis, online Survey Tools, Deliberative Survey Tools, Content Analysis 
Tools, Content Management Tools, Collaborative Management Tools, Computer Supported Cooperative Work (CSCW), Collaborative Environments, Consultation Platforms, Argument Visualization Tools, or Natural Language Interfaces

\section{Technology Categories}

It contains all technologies that are used to provide participation tools. These technologies are defined as the way eparticipation is provided to the stakeholders. One or more technologies can be the based to provide certain ICT tools.

DEMO-net (2008) lists the technologies that could harness e-participation service to citizens such as : e-Petition systems Webcasts, e-Voting and e-Referenda Podcasts, e-Consultation systems Wikis, Virtual community systems Blogs, Online surgeries and chat rooms GIS and mapping tools, e-Panels Alert services, Online newsletters / list serves Participation discussion forums, e-Deliberative polling FAQs, Suggestion tools for planning procedures Web portals, Quick polls Groupware tools, Decision-making games, Search engines, Surveys.

In general, Technologies should be integrated with web services in terms of providing it electronically, to be efficient, effective and available as online forms. Tambouris et al. (2007) specify certain technologies used in web servicing, such as : Extensible Markup Language (XML), Security Protocols (e.g. SSL), Agent Technologies, Data Mining, Ontological Engineering, Computational Linguistics, Natural Language Processing (NLP), Identity Management, and Filtering Technologies

Tambouris et al. (2007) developed a framework of five stages that were derived from the same 3-layers analysis framework discussed earlier. A country can shift from the top-down to the bottom up approach. Top down approaches mean that the government will start with defining eparticipation area, then generate the other element of e-participation. However, the
Bottom-up is about defining the technology needed before E-Participation tools and area. Both of the two approaches consist of the democratic process, the-Participation scope such as citizens and business, the techniques that are used to participate, the tools that are used to support this participation, and finally addressing the technology of participation. Only the direction is distinguished. This framework is more comprehensive as it divides eparticipation area (first layer in analysis framework) into other dimensions towards implementing e-Participation.

In addition, Phan and Kankanhalli (2007) presented a framework of e-Participation in terms of objectives and ICT supportive tools. The framework contains two dimensions; one is e-participation objectives and the other is ICT tools that can support these objectives.

This framework is an uncompleted one to represent the framework of e-participation process that includes only the objectives and related ICT tool. In addition, there were some limitations of this framework presented by Islam (2008) that the researchers did not consider the external environment, i.e. social, technical and economical and there is no clear concern about the type of participants and their attitude. The focus is on the costly tools such as online web-based that are difficult to acquire in some countries.

In response, Islam (2008) developed a model that consists of seven phases of implementation of e-Participation models. This model uses the bottom up approach that is based on the project life cycle.

\section{Rules of Engagement}

This dimension includes the information required by the users to make the eparticipation process successful. It includes rules that are assigned by the eparticipation service provider to inform the users to follow certain procedures. It normally depends on the type of action, level of impact, the sensitivity of the action and authority of the users. In addition, it contains the procedure of using this 
information and what type of actions do the users authorize to do while they are using e-participation tools. Tambouris et al. (2007) and Panopoulou et al. (2008) described the rule of using the tool as "record the information on what personal information will be gathered as well as to what citizens are allowed to do while using the tool".

\section{Duration \& Sustainability}

This dimension reflects the duration that the e-participation provider will give to the citizens to be involved in e-participation services. E-participation service duration could be one-off pilot, partially implemented based on objectives, or regularly available. The choice of duration will depend on the objectives of eparticipation service, the required size of respondents, or the emergence of service result.

The sustainability of e-participation on the other hand is the lifetime that eparticipation implemented with respect to any contingency situation related to environmental problems, energy disconnecting, error recovery, or security hacking. Pokorny (2012) presents three components of sustainability that electronic government services should develop including Society, Environment, and Economy sustainability. As eparticipation is one of the government services, it should consider these factors in the development of e-participation services. He described them as follows:

Society sustainability: The e-participation services will be society sustainable as they target all citizens and supported by any variances technology used. Thus, they should be accessible by the technology used by society (e.g. Smart phone). The eparticipation services should also be reached by all society components, with respect to gender categories, economic ability, or health disability.

Environment sustainability: The eparticipation services should use the resources effectively. Applying green (ICT) is one of the solutions that could be applied by the e-government. Also, there should be error recovery for electronic disconnecting or system crashes while using eparticipation services specially when there is natural disaster.

Economy sustainability concerns all the factors that deal with the budget for eparticipation implementation. Thus, it concerns the availability of funding resources that enables the ongoing technology and improves it over time. The effective use of the resources used in eparticipation services should also be considered in economy sustainability

\section{Accessibility}

The issues of how the target groups reach the product and what number of access per time all reflect the accessibility of eparticipation. The government should consider all the challenges and barriers that make citizens not included in the eparticipation session. The available technology should overcome any disability of citizens regarding "age, economic situation, education, geographic location, language, etc." (W3C, 2012). Panopoulou et al. (2008) list the accessible tools used in eparticipation that include Internet channel use by PC, Mobile channel, Public Kiosks, Digital TV, Non internet channels.

Resources and Promotion

Macintosh (2004) stressed on understanding the financial implications of using ICTs to support participation. Resources are what can be used to support or generate a set of outcomes and promotion is the tool that answers the question how will to be known to others. These two issues are more discussed below:

\section{E-participation Resources}

There are many resources that should be used for a better e-Participation implementation. They are as follow:

Communication channels: In order to make e-Participation successful, the government will need to start involving communication channels to make the 
citizen's voice heard with minimum amount of effort. Those communication channels can be: chat, e-mail, communication maps, mms, webcasts, forums, surveys, blogs, and contact management system. In addition to the above-mentioned items, the items should be two way communication tools otherwise they will be like informative tools which are not that beneficial for e-participation, i.e. a win-win situation.

Human Resources are one of the most important component capital involved in an e-participation project. Those skills need to be combining between administrative, commercial, management and technical. The challenges evolve from training and building qualified employees. The best solution is to keep the environment updated with the latest training programs.

Cost against Budget: To build a clear idea and a transparent relationship between the government and the citizen, statements and policies should be transferred to actions based on users' demand. Any use of a new tool (technical or human resource) will cost the government a great amount of budget to implement the plan. The government and citizens should have a way to discuss the investment proposals, the projects list which is worth looking at and make a budget study. In this sense, citizens can provide the government with feedback on what could work and what will be a waste of time and money. Using decision analysis tools and negotiation, the government will conclude a number of modules according to the feedback and participant's votes.

Time and Management are powerful constraints in the project. The duration starts from planning until implementing. As for any project, the critical path focused on key tasks to complete the project on time. Under this very important factor, a change in management is a major problem especially in the public sector because of administrative and political practices. Contributions and participation could be a key of change in management when they go the wrong direction.

\section{E-participation Promotion}

Traditional promotion tools are the tools which existed before the 21 century such as TV, radio, newspaper, magazines, broachers, advertisement boards, mail and etc. Those tools could not actually give citizens the whole experience of delivering their voices, neither could it provide the government with the citizens' valuable feedback. Century promotion tools are one of the tools which everyone uses for personal, business or organizational purposes. Those tools are Social network (twitter, Facebook, Instagram, YouTube, blogs, wiki etc...). Today those tools can create a bridge between the participant and the government through direct communication. They are online and available to everyone with the same privileges.

\section{Evaluation and Outcomes}

Macintosh (2004) declares that there is no clear evaluation framework to merge both "quantitative and qualitative metrics". In response, Macintosh and Whyte (2008) came up with a framework for evaluating e-participation projects. This framework considers three layers that e-participation influences. These layers are Political, technical, and social perspectives. There is a set of three main criteria that affects eparticipation projects such as democratic criteria according to national e-democracy, which is about "what the projects should do to support and enhance democracy"(Macintosh and Whyte, 2008). An e-participation project should achieve all or more than one of democratic criteria.

They emphasized that project criteria are the second aspect that should be considered in evaluating e-participation project. They include: engaging with a wider audience, obtaining better informed decision, enabling more in-depth scrutiny to provide more than information, cost effective analysis of contributions, and providing feedback to citizens. These criteria will ensure that the project of eparticipation will follow the right path and achieve success. Finally, as far as the sociotechnical criterion is concerned, it is about 
both social and technical criteria that influence democracy in the country. According to the social perspective, the project should deliver 'trust and security', and 'relevance and legitimacy' with citizens' needs. Regarding the technical perspective, the usefulness and usability of projects are important. To make the project a useful project, it should be 'accessible', 'appealing', and 'responsive'. To ensure its usability, the e-participation application should contain usable 'navigation', 'efficient and flexible' with error recovery (Macintosh and Whyte, 2008).

\section{Critical Success Factors}

According to Macintosh (2004), the importance of this phase is to "ensure that we capture any political, legal, cultural, economic, or technological factor that stands out so as to make e-participation a success. There is a number of critical success factors that must be considered in e-participation implementation as follows: first, the process of e-participation must be open and transparent; second, the citizens should be engaged in the design processes; third, participation must encourage the idea of having a better society where the real democracy is fundamental; forth, develop the right tools and procedures to enhance the e-Participation processes and results; fifth, making sure there are criteria of success regarding the citizens' engagement; sixth, choose the right technology to reach all the different levels (education, wealth, interest) of citizens; seventh, check on the quality of the online environment; eighth, is the quality of the content and well presentation because it is one way of showing citizens that the government cares; ninth, prioritize the feedback and deliver the important before the less important; and finally, always make sure to allow different opinions to be shared and expressed.

\section{E-Participation in the Kingdom of Bahrain}

E-Participation is one of the trends that the Kingdom of Bahrain has involved in its 2012-2016 vision. According to the United Nations' e-Government Survey in 2014
(UN, 2014), it is indicated that Bahrain had a big improvement in involving citizens in the government process. It is ranked as the 14th internationally in the development of E-participation.

Bahrain vision for 2016 is to "achieve next generation e-Government excellence by delivering high-quality services effectively, valuing efficiency, advocating proactive customer engagement, nurturing entrepreneurship, collaborating with all stakeholders and encouraging innovation". The first strategic objective is to increase public engagement and participation. In fact, it started very strongly by considering the feedback, and communicates with the citizens in order to be powerful in adopting E-participation tools at a very high level of maturity as a vision for 2016 eGA (2012).

E-government Authority (eGA) at the Kingdom of Bahrain is the provider of eparticipation services. This makes studying the readiness of the technology provider an essential part of our study. In this section, e-participation project readiness from the government's side at the Kingdom of Bahrain will be evaluated based on Macintosh (2004)'s dimensions of readiness evaluation using the information posted on the website of e-government of the Kingdom of Bahrain (www. Bahrain.bh)

\section{Level of Participation}

As a first plan, the Kingdom of Bahrain focused on providing information and informing the Bahraini citizens with the latest news regarding the political area. eGA then activated the citizens' power by enabling interaction between both the Authority and the concerned stakeholders in political making. The Kingdom of Bahrain is now at e-consultation level. The aim of e-consultation is to serve citizens in the best way, documenting issues or opportunities, giving advice, hearing citizens and getting feedback (www.Bahrain.bh).

E-participation was activated approximately in all ministries in the Kingdom of Bahrain after it was focused in political sectors, by representative website 
that is called Alnuwab website (http://www.nuwab.gov.bh). Thus, eGovernment authority provided eparticipation in the education field (http://www.moe.gov.bh). The Ministry of Interior considered the compliance that related to crime, as well as the feedback from society through social media (http://www.interior.gov.bh). The Health ministry and the ministry of culture focused their e-participation on getting feedback and considered to improve situations (http://www.moc.gov.bh) and (http://www.moh.gov.bh), etc. For the areas of e-participation, the Kingdom of Bahrain focused on information provision, community building and collaborative environment through different accessible channels that will be discussed later.

\section{Stages in the Policy-Making Process}

E-Government Authority pointed to stages of e-participation process in the website of Bahrain.bh. Thus, it starts with publishing the document. The published document includes: topic description, impact of process, information and guideline related decision making, timeline of e-participation process, the resources required to complete the session, and the constraint of engagement. The second step is to broadcast the document and create the users' readiness about the published topic in which the broadcasted document will be published through communication tools to be accessible by the target users. The egovernment authority collects Feedback/ responses from the user within assigned timeline. The third step, the Analysis of the responses will take place. The analysis will consider the opinion and suggestion related to generating certain decision making. Then, the decision will be announced through appropriate communication media. Finally, the stage of Closure and Archive will take place after successful decision making where the failed process will be monitored and returned to the first stage.

The Kingdom of Bahrain policy process making mainly matches with Macintosh (2004) standard, but Macintosh (2004) does not consider the archiving process.
Archiving is a very important process to hold the historical data and responsiveness of Citizens for future use

\section{Actors and Roles}

The Kingdom of Bahrain government is ready to engage different types of stakeholders. E-Government Authority mainly engages both citizens (G2C) and government ministry (G2G). The individual includes: citizens, residents, non-residents (e.g., tourists, business travelers), corporations, NGOs, or representatives of the aforementioned wishing to engage on social media.

\section{Technologies}

E-government authority is ready to hold any new technology. They had a full team of research and development, quality assurance, technology development, and customer service and compliance. Most of ICT tools of e-participation come to achieve the main objective such as enabling the consultation between civil society sectors.

The available ICT tools provided in the eparticipation project are fully installed in some ministries' websites or semiimplemented in other ministries as mentioned before. The ICT tools used by eGovernment Authority is virtual community system blogs, online newsletters in most ministries, online surgeries and chat rooms, e-deliberative polling, FAQs, Quick polls, Groupware tools, and surveys.

The technology used to provide eparticipation services based on security protocols, Collaborative environments, Mobile and wireless technologies, Semantic web services and Streaming mediaWeb 2.0 features.

\section{Rules of Engagement}

It is also known as the code of conduct. The e-government of the kingdom of Bahrain describes certain rules to follow when citizens engage in certain communications. This means that there is readiness in terms of initializing rules of engagement in 
e-participations services. Some rules of engagement according to the eGovernment Authority of the kingdom of Bahrain are: " The post/comment originator shall identify themselves by their name, and if relevant, by their position and organization, posts/comments can be made in Arabic or English, posts/comments should be made as clear and concise as possible in order to allow the government to understand, reply and take the suitable measures if necessary, posts/comments shall not be repeated on public communication channels (e.g., forum, blog or social media) finally, all communications are subject to relevant laws and regulations".

\section{Duration \& Sustainability}

All e-participation services provided to the concerned users are provided in regular basis which is open to use, comment and view by the public. Social media, blogs, newsletters are examples of the open services provided by the eGA. In some cases there will be some services that are private and target certain groups. eGA holds different services with flexibility to select the type of engagement.

According to the sustainability of eparticipation, researchers found the eGA is ready in terms of the sustainability factor of e-participation such as: society, and environment. According to the Society factor, eGA in general adopts all services to return value to society with different variances of the technology used. It is also trying to provide e-participation services to all citizens with no exception including the people with disability through many tools such as LISTEN tool

According to the Environment factor, eGA tries to build a safe environment to hold data, supported with an error recovery system in responses with any unacceptable situation. According to security, egovernment in regular basis checked security by McAfee security, as well as it is also powered by Norton security. EParticipation services also are provided through a secure environment with TRUETs certificate for holding users' privacy. Finally, e-GA tries to implement green IT on most of its transactions to keep the environment sustainable.

\section{Accessibility}

eGA enabled e-participation services through certain tools. These accessibility tools are provided to community sectors for better e-participation. E-participation could be accessed via electronic media such as internet, mobile, kiosks, workshop and conferencing facility, and National Centre. It also provides a Call Center to allow users to communicate directly with the provider.

\section{Resources and Promotion}

eGA is a part of the kingdom of Bahrain ministries, in which its budgets are assigned in every first quarter of year. This budget assigned is distributed to many projects that can help individuals and businesses in the Kingdom of Bahrain. Mainly, the source of funding depended on local public funding. It used a wide range of promotion tools in terms of informing the users with the latest news, and provided technology. These promotion tools are TV promotion, radio and News, Newsletters and magazines, Social media, Broadcasting through mobiles and e-mails, through websites and clickable logos advertising.

\section{Evaluation and Outcomes}

In this section, the design of ICT of eparticipation will be evaluated regarding three evaluation perspectives. These perspectives are: political, project and social-technology perspectives.

\section{Political perspective}

E-participation at the Kingdom of Bahrain aims at enabling the transparency between community sectors, enhances the engagement of users, and betters the recognition of conflict and consensuses within the political area.

\section{Project perspective}

ICT designed for e-participation project at the Kingdom is not only engaging citizens 
but it is also engaging wider audience such as residents, and non-residents. The project of e-participation also enables citizens to participate in addition to providing information as well as enabling effective analysis of results as the data transfer directly to the analysis stage, and then providing feedback to citizens.

\section{Social-technical perspectives}

eGA enables different types of techniques that increase the readiness of social involvement in the e-participation project through enhancing the users' accessibility and responsiveness to the available tools and objectives. On the technical perspective, e-Government Authority has unified navigation to enhance users' convenience and innovation that directly affect the readiness of using technology. The available technologies are also efficient and flexible for improvement and enhancement, and they are supported with an error recovery system embedded with the archives of responses and suggestions from the users.

\section{Critical Success Factors}

There are many CSFs to measure the performance of the e-participation project. According to eGA website, they indicated that they have many procedures to follow to make the e-participation provider ready for any situation related to managing and getting responses and issues. These CSF's are:

- E-participation has to maximize transparency.

- All comments and questions are to be answered and taken under for consideration to maintain the existing situations.

- Acknowledgment has to be published through channels for encouraging citizens to be involved.

- The progress of e-participation is to be documented, updated and provided to citizens in a way to keep them updated with all government practices.

\section{Conclusion}

This research was conducted to evaluate the readiness of e-participation in the Kingdom of Bahrain from the government side.

The evaluation showed that the Kingdom of Bahrain has an excellent progress and readiness toward implementing the eParticipation project according to the ten dimensions of e-participation of Macintosh (2004) implementation evaluation model that was applied in this research. Thus, they are in a stage of applying econsultation which is the second level of eparticipation. They applied e-participation to include many sectors including Education, Science and Research, Communication, Local/Regional community development, Politics and Social Services, reaching different actors including individual citizens, elected representatives, government ministries, NGOs, mass communication, non-residents, tourists and businesses. They are using certain technologies such as e-petition, econsultation, blogs, online newsletters, polling and electronic surveys. They provide actors with different channels to use e-participation services including Kiosk, Non e-channel through call centers, Mobile channels and portals. Also, they are promoting their e-Participation services through TV promotion, radio and News, Newsletters and magazines, Social media, Broadcasting through mobiles and e-mails, Traditional methods (telling friends), clickable logos advertising and Journal and conferencing. On the duration and sustainability dimension, it depends on the type of e-participation which could be oneoff pilot, partially implemented based on objectives, or it could be available regularly. According to the evaluation, the Kingdom of Bahrain paid attention to the successful implementation of the eparticipation project through political, project and social-technology perspectives. Thus, they are striving to be transparent, ensure political Equality, and enhance Engagement in the political perspective. In project evaluation, they are engaging with 
wider audiences and providing information feedback. Finally, in the Social-technology perspective, the Kingdom of Bahrain provides user accessibility, user responsiveness, unified navigation, and error recovery system. For the Critical success Factors, the Kingdom is working

\section{References}

1. Arnstein, R. (1969), 'A Ladder of Citizen Participation', Journal of the American Planning Association 35 (4), 216224.

2. Bremen.(2008), "eParticipation Electronic Participation of Citizens and the Business Community in eGovernment". [Online], from: http://www.ifib.de/publikationsdateien/st udy_e-participation_engl.pdf

3. Brown, M. B. (2004), 'The Political Philosophy of Science Policy', Essay Review of Science, Truth, and Democracy, Minerva, 42(1), 77-95.

4. Clift. S. (2003), "Exploiting the Knowledge Economy: Issues, Applications, Case Studies". [Online], from: http://www.publicus.net/articles/edempu blicnetwork.html

5. DEMO-net. (2008), D10.5: eParticipation research projects at local, regional, national, and EU level, DEMO-net - The eParticipation Network

6. DiNitto, D. \& Johnson D. (2011), According to Essentials of Social Welfare: Politics and Public Policy (Connecting Core Competencies)'. Prentice Hall.

7. eGA(2012) "Summary National eGovernment Strategy 2016". [Online], from:

http://www.ega.gov.bh/wps/wcm/connec t/1f75f0004af9c3b2b84cb978e38c6a11/e Gov\%2BStrategy_Brochure_Eng.pdf?MOD= AJPERES

8. Islam, S., (2008). "Towards a sustainable e-Participation implementation model". [Online], from: http://unpan1.un.org/intradoc/groups/pu very hard to target the initial stated CSFs with very rigid follow up procedures.

As a future work, this research will be extended to investigate the impact of the eparticipation project on the citizens' quality of life.

blic/documents/undpadm/unpan038387.pdf.

9. Macintosh, A. and Whyte, A. (2008),'Towards an evaluation framework for eParticipation, Transforming Government :People, Process \& Policy, 2 (1), 16-30.

10. Macintosh, A. (2004), 'Characterizing E-Participation in Policy-Making, ThirtySeventh Annual Hawaii International Conference on System Sciences (HICSS-37), January 5 - 8, Big Island, Hawaii.

11. OECD (2008) 'Citizens at the Centre: public engagement for better policy and services', 38th Session of the Public Governance Committee, 24 October 2008, OECD, Paris.

12. Panopoulou, E., Tambouris, E., Tarabanis, K. (2008)," eParticipation good practice cases and diffusion". [Online], from: http://www.europeaneparticipation.eu .

13. Phang C. W. \&Kankanhalli, A. (2007), 'A Framework of ICT Exploitation for EParticipation Initiatives', ACM, 51(12),128132.

14. Pokorny, G(2012) "Using e-Governance to Advance Sustainable Development". [Online], from: http://www.unosd.org/content/document s/Using\%20eGov\%20to\%20Advance\%20S ustainable\%20Development_(20121111_G regory_Pokorny)_Final_Draft.pdf.

15. Tambouris E., Liotas, N., Kaliviotis, D., and Tarabanis K., A (2007), 'Framework for scoping eParticipation'. Proceedings of the 8th Annual International Digital Government Research Conference, May 20-23, 2007, Philadelphia, USA, 288, 289. 
16. UN.(2014), "E-Government for the future we want". [Online], from:http://unpan3.un.org/egovkb/Portal s/egovkb/Documents/un/2014-Survey/EGov_Complete_Survey-2014.pdf , 2014
17. W3C. (2012), "Designing for Inclusion”, [Online] from: http://www.w3.org/WAI/users/Overview. html. 